This item was submitted to Loughborough's Research Repository by the author.

Items in Figshare are protected by copyright, with all rights reserved, unless otherwise indicated.

\title{
Modelling the satisfaction of contractors: the impact of client performance
}

PLEASE CITE THE PUBLISHED VERSION

http://dx.doi.org/10.1108/eb021239

PUBLISHER

(c) Emerald

VERSION

AM (Accepted Manuscript)

\section{PUBLISHER STATEMENT}

This work is made available according to the conditions of the Creative Commons Attribution-NonCommercialNoDerivatives 4.0 International (CC BY-NC-ND 4.0) licence. Full details of this licence are available at: https://creativecommons.org/licenses/by-nc-nd/4.0/

\section{LICENCE}

CC BY-NC-ND 4.0

\section{REPOSITORY RECORD}

Soetanto, Robby, and David G. Proverbs. 2019. "Modelling the Satisfaction of Contractors: The Impact of Client Performance". figshare. https://hdl.handle.net/2134/16603. 


\title{
Modelling the satisfaction of contractors:
}

\section{The impact of client performance}

Robby Soetanto and David G. Proverbs ${ }^{1}$

\author{
Built Environment Research Unit \\ School of Engineering and the Built Environment \\ University of Wolverhampton \\ United Kingdom
}

1. Author for correspondence

Built Environment Research Unit

School of Engineering and the Built Environment

University of Wolverhampton

Wulfruna Street

Wolverhampton WV1 1SB

E-mail: D.Proverbs@wlv.ac.uk

Phone: 01902322786

Fax: 01902322743 


\title{
Modelling the satisfaction of contractors: The impact of client performance
}

\begin{abstract}
An assessment of the performance of UK clients on 55 'case projects' as considered by contractors is presented and used to develop models of contractors' satisfaction. Principal component analysis reveals five dimensions to contractor satisfaction, classified in this research as (i) 'support provided to contractors', (ii) 'clients' attitude', (iii) 'clients' understanding of their own needs', (iv) 'quality of clients' brief', and (v) 'financial aspects of performance'. Knowledge of these models should enable clients to perform better, which is conducive towards satisfactory participant performance and overall project performance. The models identify three key aspects of client performance that are found to significantly influence contractors' satisfaction levels, namely (i) the capability of the client's representative, (ii) the client's past performance and project management experience, and (iii) the financial soundness and reputation of the client. Additionally, the nature of the project and certain characteristics of contractors also influence satisfaction levels. The models demonstrated accurate predictive power and were found to be valid and robust. Clients could use the models to help improve their performance leading to more successful project implementation. This will also promote the development of harmonious working relationships within the construction project coalition.
\end{abstract}

Keywords: client performance criteria, multiple regression analysis, performance and satisfaction attributes, performance assessment 


\section{INTRODUCTION}

Traditionally, the main participants of the construction project coalition (PC) are the client, the architect and the contractor. The interactions and interrelationships between these participants largely determine the overall performance of a construction project (Smith and Wilkins, 1996; Egan, 1998). The performance of these participants is also interdependent (Higgin and Jessop, 1965; Mohsini, 1989). Hence, in order to perform effectively, a reciprocal requirement exists, whereby each participant requires the other participants to perform their duties effectively and in harmony with the others. Notwithstanding this mutual dependency, the performance of individual participants remains important because overall project performance is a function of the performance of each participant (Liu and Walker, 1998).

In the context of the construction PC, the satisfactory performance of participants is also recognised as a pre-requisite to maintaining harmonious working relationships. Furthermore, harmonious working relationships are essential if projects are to be successful (Baker et al., 1988; Smith and Wilkins, ibid.; Egan, ibid.). There is a need therefore, for key participants to assess each other's performance on a mutually agreeable and regular basis. That way, they can monitor and seek to continuously improve their own performance for the benefit of the overall project.

This paper describes the findings of such an assessment based on the views of contractors with respect to the performance of clients. Several models of contractor satisfaction are subsequently developed and presented. Data were collected through a questionnaire survey in which contractors were asked to assess the performance of their clients. Multiple regression techniques were used to identify significant attributes influencing expressed satisfaction / 
dissatisfaction (i.e. levels of satisfaction). The models can be used to predict contractor's satisfaction levels derived from the performance of clients at various project stages (e.g. before commencement of work on site); thereby enabling suitable actions to be implemented to address areas of concern. This may ultimately help enhance overall project performance due to a more co-operative and performance enhancing PC.

\section{DETERMINANTS OF SATISFACTION IN THE PERFORMANCE ASSESSMENT}

Figure 1 illustrates the relationship between performance and satisfaction in the context of performance assessment. Performance outcomes are the input and levels of satisfaction / dissatisfaction are the output. Between the input and output, a psychological processing or 'black box' exists. That is, an observer can see only what goes in and what comes out, not what occurs inside (Oliver, 1997). Additionally, this psychological process is subjective and difficult to interpret. Satisfaction is regarded as an internal frame of mind, tied only to mental interpretations of performance levels (Oliver, ibid.). This indicates that a performance assessor (e.g. contractor) will have their own psychological interpretation of the performance of others (e.g. clients).

Smith et al. (1969) argued that satisfaction can be specifically defined as a function of the perceived characteristics of a performer in relation to an assessor's frame of reference. They further stated that for given situations, expectations, and experience play important roles in providing the relevant frame of reference. Here, frame of reference is defined as the internal standard (or standards) a person uses in making an evaluation. Individuals may have different standards in their judgements of performance. Different persons enter the same objective situation with different frames of reference, which affect both their summary evaluation of the situation and the aspects of that situation which are pertinent to their judgements. Better 
understanding of the judgements made by individuals can be obtained through knowledge of their frame of reference.

However, gaining knowledge of an individual's frame of reference is considered a very onerous, if not impossible, task. Investigating underlying attributes forming an individual's frame of reference is relatively easier. From this, it is argued that an assessor attributes, i.e. satisfaction attributes, may influence their judgements of performance.

\section{CONCEPTUAL MODEL OF PERFORMANCE ASSESSMENT}

Conceptually, the outcomes of performance assessment (in terms of levels of satisfaction) can be influenced by two major attributes, those of the performer (i.e. performance attributes) and those of the assessor (i.e. satisfaction attributes). Satisfaction attributes are differentiable from performance attributes mainly due to their unique nature; they being inherent within an individual (i.e. assessor). That is, performance attributes may reflect on both participants and projects, and will influence both participant and project performance. In contrast, satisfaction attributes reflect on the assessor and influence his/her performance assessment and as such are beyond the control of the performer.

Performance attributes consist of participant attributes and project attributes. Participant attributes represent the characteristics or nature of a particular participant or their organisation, such as company age, turnover, etc. Project attributes represent the characteristics / nature of a project, comprising attributes which may be outside the control of the participants. Controllable attributes are for example forms of contract, procurement route, extent of design finished prior to work on site. Uncontrollable attributes include type of project and building, and ground and weather conditions. 
Satisfaction attributes include the personal characteristics of the individual assessor (e.g. experience, vocational background) and of their employer, which may influence their assessment (e.g. company age, turnover, number of employees).

Figure 2 demonstrates the relationships between the variables employed. The performance attributes of a participant have a direct influence on their own performance in the construction process. Project attributes indirectly influence the participant's performance since the attributes may enable / hamper the participant in executing their duties. Performance assessment in this respect is considered as 'objective' (i.e. more tangible) in nature. For example, contractor performance may be assessed in terms of cost, time and quality performance (Holt, 1995).

However, performance assessment goes beyond objective aspects outlined above since it involves the feelings of the assessor, which in turn is dependent on their background, i.e. frame of reference. This assessment is considered 'subjective' and at a higher level. This research embraces both 'objective' and 'subjective' (or higher level) performance assessment. In this case, satisfaction is measured using predetermined performance criteria, which are explained in the next section.

A list of all performance and satisfaction attributes (as independent variables) identified from a thorough review of the literature is presented in Table 1 (column 1). Using the correlation technique, possible significant variables for modeling were selected and are shown in column 4. Some degree of multicollinearity was found to exist in several groups of variables. To rectify this problem, those variables which were highly correlated were combined into a 
single indicator as suggested by Lewis-Beck (1993) and Dunteman (1994). Four combined variables were obtained from this process, namely CLATCAPA, CLATFILI, CLATEXPE and CLATPPAU. CLATCAPA was interpreted as the 'capability of the client's representative'. CLATFILI was interpreted as 'financial soundness and reputation' of the client. CLATEXPE was interpreted as 'previous experience in similar projects and working relationship with contractor'. CLATPPAU was interpreted as the client's 'past performance and project management experience'. The variables used for modelling are presented in column 5 of Table 1.

\section{CLIENT PERFORMANCE CRITERIA}

In the context of this paper, client performance criteria are defined as those used to measure the performance of clients based on the views of contractors. These criteria were determined through earlier interviews with nine top UK contractors and also supported by literature review in the domain of (client) performance. These criteria were categorized under several main headings. A full list of the criteria identified is presented in Table A1 in Appendix A.

\section{RESEARCH METHODOLOGY}

To provide the main modelling data, a questionnaire was developed based on the attributes and performance criteria identified. Respondents (i.e. contractors) were asked to identify a recent (i.e. within 2 years) UK building project in which they were involved (referred to as the 'case project'). Respondents were asked to relate all their answers to the questions contained in the questionnaire to this one 'case project'. This strategy was designed in order to capture a true and realistic reflection of contractors' satisfaction / dissatisfaction feelings. To protect the confidentiality of the other parties involved in these case projects, respondents were not asked to identify projects, nor name other participants. 


\section{The survey}

Following the development of the questionnaire and implementation of a pilot survey, a UKwide questionnaire survey of contractors was conducted. Distribution involved 511 top UK contractors identified from the listing of Key British Enterprises (Dun and Bradstreet, 1998), the Kompass Directory (1999-2000) and chartered building companies (CIOB, 1998/1999).

Overall, eighty responses were received representing a 15.7 percent response rate. This relatively low response rate is about the 'norm' for this kind of construction management research and in many ways can be associated with the 'confidential' nature of the questions and the comprehensive nature of the research instrument.

\section{Dimensions of contractor satisfaction}

In this research, satisfaction is measured using an interval scale (i.e. scale 0-10) which assumes that satisfaction is a matter of degree, not an all or none property. To measure an abstract concept such as satisfaction, the concept should be defined at an operational (i.e. lower) level (as various performance criteria identified), which is observable and directly measurable (Johnson and Fornell, 1991). If the relationship between the abstract concept and the operational definition of satisfaction (i.e. performance criteria) is strong, the measurement instrument can be considered as valid and reliable to represent the abstract concept (Carmines and Zeller, 1979).

Dimensions of contractor satisfaction were derived using the principal component analysis (PCA) technique, applied to the performance criteria of 55 responses (i.e. case projects). The main purpose was to determine the number of common components (i.e. satisfaction 
dimensions) that would satisfactorily produce the correlations among the observed variables (Kim and Mueller, 1978). A brief description of this technique is presented in Appendix A.

Five dimensions of contractor satisfaction were obtained from this process. The scores of the performance criteria under each dimension were then averaged to obtain the satisfaction measure (i.e. component score). Nunnally (1978) demonstrated how combined scores were more valid and reliable than individual scores alone. The component score serves as an index of attitude towards a particular dimension of satisfaction under investigation (Torbica, 1997). From the original 33 performance criteria, 22 were included in one of the five dimensions, which were interpreted as (i) 'support provided to contractors', (ii) 'clients' attitude', (iii) 'clients' understanding of their own needs', (iv) 'quality of clients' brief', and (v) 'financial aspects of performance'. Additionally, two further measures were derived from the mean of these five dimensions (the average satisfaction) and the overall satisfaction of contractors derived from one question in the questionnaire. The overall satisfaction is unique because it represents individual satisfaction scores as expressed by contractors.

The validity of the satisfaction measures were investigated via an assessment of their content, criterion-related and construct validity. The reliability of the measures (in terms of their internal consistency reliability) was assessed using coefficient Cronbach’s alpha. For a full description of the validity and reliability of empirical measurement, readers may wish to consult Bohrnstedt (1970), Nunnally (1978), Carmines and Zeller (1979) and Litwin (1995). In construction, Torbica (1997) used a similar method for testing the validity and reliability of satisfaction measures of home buyers. 


\section{CONTRACTOR SATISFACTION MODELS}

Based on a sample of 55 case projects, seven multiple regression models were developed to describe levels of contractors' satisfaction arising from the performance of their clients, using satisfaction measures as dependent variables, and performance and satisfaction attributes as independent variables. For each model, one satisfaction measure was used as the dependent variable and performance and satisfaction attributes as independent variables. This was repeated for each of the satisfaction measures. The use of multiple measures of satisfaction allows comprehensive determinants to be identified and hence, a complete understanding of contractor satisfaction based on client performance to be obtained. The multiple regression technique was chosen because of its ability to predict levels of satisfaction. A brief description of this modelling technique is given in Appendix $\mathrm{B}$. The models are mathematically presented in Table 2, where significant independent variables identified are arranged in descending order of importance.

The models explain 57 to 75 percent of the variations in the dependent variables, which was considered reasonable because of the subjective nature of the research (i.e. expressed satisfaction feelings, subjective attribute evaluation), and the presence of somewhat 'noisy' data. The remaining 25 to 43 percent of the variations were unexplained by the models. This indicates that there might be cases where the models are inaccurate and therefore the models have to be interpreted with caution. The models were then assessed for their validity and reliability using a hold-back sample of 17 questionnaires (i.e. case projects) that had not been used previously to develop the models, as described in Appendix C. The results confirmed the validity and robustness of the models in predicting contractors' satisfaction levels. 


\section{Results and discussions}

For the first model, support provided to contractors, four independent variables were found to significantly determine satisfaction levels, these being (i) the capability of the client's representative, (ii) the extent to which the project was overbudget, (iii) the distance of the project from the client's home office, and (iv) the extent to which the design was complete before commencement of work on site. All but the second variable demonstrated a positive relationship with support provided to contractors.

It is not really surprising that contractors are very much dependent on the capability of the client's representative. Capable representatives allow contractors to perform better and hence meet their expectations and satisfy their clients. The extent to which projects are overbudget suggests that contractors are directly affected by the financial health of the project. Surprisingly, the further the distance between the client's head office and the project, the higher contractors' satisfaction levels. Perhaps, there is a greater tendency for the client to interfere and disrupt day-to-day progress when located close to the project, thereby impacting contractor performance. The model also suggests that contractors prefer to be engaged on projects that are designed prior to commencement of work on site. This often allows contractors to progress without delays and variations and thereby improving overall project performance and satisfaction levels.

Satisfaction levels arising from the clients' attitude were significantly influenced by (i) the capability of the client's representative, (ii) the extent to which the project was overbudget, and (iii) industrial building projects. 
The capability of the client's representative was found to make the greatest contribution to this aspect of satisfaction. Here, a cooperative and supportive attitude which encourages proactiveness will help to improve project performance and enhance satisfaction levels. Projects overbudget were again found to lower satisfaction levels. A concerted approach is needed from all involved in the construction PC, not only clients and contractors. It is interesting to note that, for industrial building projects, contractors were found to be less satisfied with client performance. This may be connected to the lack of prominence and publicity associated with work of this kind.

Contractors' satisfaction levels arising from clients' understanding of their own needs were found to be dependent on (i) the capability of the client's representative, (ii) a perception that clients always change their mind, and (iii) clients from the industrial sector. Again, the capability of the client's representative makes the greatest impact on satisfaction levels. Here, a capable representative will help to deliver clear and definitive project requirements, hence help to enhance overall project performance. It is interesting to note that contractors' perception of clients was significant indicating the presence of subjectivity in their performance assessment. The model also suggests that contractors are less satisfied when working for clients from the industrial sector. This is coincident with the previous model (i.e. clients' attitude) where contractors were found to be less satisfied with client performance in industrial building projects.

Satisfaction levels arising from the quality of clients' brief were dependent on (i) the client's past performance and project management experience and (ii) a perception that clients always want to minimise cost without considering quality. This suggests experienced clients may have better performance in the formulation of the brief and in their understanding of the 
building process. Furthermore, some degree of subjectivity was again found to be present in the performance assessment.

The client's financial soundness and reputation was found to be the only significant predictor for satisfaction levels arising from financial aspects of performance. This is interesting in that financially sound and less litigious clients are more likely to provide adequate funding for the project and to reimburse their contractors on schedule. Such financial issues are often the cause of disputes amongst the project participants and sometimes lead to court action.

The average satisfaction model confirmed (i) the capability of the client's representative, (ii) the financial soundness and reputation of the client, (iii) contractor size measured in terms of number of employees, and (iv) client's communication channels as useful predictors. As before, the client's representative was found to exert most influence on contractor's satisfaction levels. Moreover, clients who are financially sound and have a good reputation, enhance satisfaction levels. The presence of contractor size suggests that larger contractors are more likely to be satisfied with client performance. Perhaps, larger contractors are more likely to encounter more experienced and knowledgeable clients, able to perform more effectively in the construction process. The model also highlights the influence of the client's communication channels, suggesting that decentralised channels bring higher satisfaction. Decentralised communication channels are known to facilitate better information flow and decision making when problems arise.

The overall satisfaction model identified (i) the capability of the client's representative, (ii) the extent to which the project was overbudget, (iii) a perception that clients regularly change their mind, and (iv) a perception that clients do not know what they want, as useful 
predictors. Here, again, the capability of the client's representative was the most influential. Contractors are less satisfied when projects are overbudget. The presence of two satisfaction attributes in the model was somewhat confusing. While a perception that clients regularly change their mind negatively influences satisfaction levels, a perception that clients do not know what they want positively influences satisfaction levels. It would seem logical that those contractors who negatively perceive their clients are less likely to be satisfied. Further research is required to investigate this aspect. Nevertheless, the results confirm that in addition to client and project attributes, characteristics of contractors also impact on their satisfaction levels.

\section{CONCLUSION}

Findings resulting from the development of the contractor satisfaction models based on client performance are summarised in a schematic model presented in Figure 3. As a framework, this model adopts the conceptual performance assessment model presented in Figure 2. Significant variables in the models were categorised into performance (i.e. participant and project performance) and satisfaction attributes. Variables which could be manipulated by coalition participants are highlighted in bold. This mode of presentation allows a summary of the significant variables, and hence provides a deeper understanding and more informed view of the model.

The models identified five client performance attributes including four which could be manipulated by PC participants to enhance satisfaction levels. The models suggest that the capability of the client's representative plays a crucial role in determining client performance, and hence, contractors' satisfaction levels. Therefore, clients need to give considerable thought to the selection of their representative as this figurehead is of utmost importance to 
the service providers. A capable client's representative is essential if the project is to be successful. Moreover, client's past performance and project management experience have also been shown to significantly influence satisfaction levels. Hence, clients with a good track record and who possess some knowledge and experience of project management are more likely to perform effectively and satisfy their contractors.

Financial soundness and reputation were found to influence contractor satisfaction levels, particularly in terms of financial performance (e.g. adequate funding, timeliness of payments). Clients should have adequate financial back-up to ensure continuous project implementation. This has been known to influence contractor's cash flow. Moreover, clients with a reputation for litigation should be avoided.

Clients who have decentralised communication channels ease communication and facilitate faster decision making. Sufficient authority should be given to the client's site personnel (i.e. representative) in order that they can make immediate and effective decisions when needed. Additionally, contractors were found to be less satisfied when working for clients from the industrial sector. The nature of a client's business is somewhat difficult to influence as, due to competitive and economic pressures, contractors are not often in a position to select their clients. Although uncontrollable variables are considered beyond the remit of the participants, this could be deemed as a warning to contractors.

Of four project attributes identified, two were considered manipulable. Projects, which overrun, were also found to lower contractor satisfaction levels. Budget overruns may be due to variations introduced by clients, in which clients bear the financial consequences. However, budget overruns also introduce further complexity, which may demand the 
allocation of additional resources, which could have a financial impact on contractors. Keeping projects to budget requires a concerted approach from all participants, not merely clients and/or contractors. Another significant attribute within the client's 'control' was the extent to which the design was completed before commencement of work on site. The model indicates that contractors' satisfaction levels are higher when design work is completed prior to commencement of work on site. Contractors prefer to have all design information as this allows more effective planning and removes the possibility of delays caused by lack of information. In contrast, the model also indicates that the greater the distance between the client's head office and the project, the higher the satisfaction. This suggests that while contractors want rapid decisions and effective communication channels, they do not want excessive interference from clients. Therefore, there is a need for clients to achieve a balance between involvement and interference in order to ensure successful project implementation and contractor satisfaction. The models also highlight that contractors are less satisfied when working on industrial projects (for industrial type of clients). This may be connected to the lack of prominence and publicity associated with work of this kind.

Satisfaction attributes, including a perception of clients and contractor size (in terms of number of employees) were found to impact performance assessment although not to a great extent. This indicates the validity of the conceptual model (refer to Figure 2) in that satisfaction attributes (i.e. attributes of the assessor) impact performance assessment. Furthermore, this also confirms the subjective nature of performance assessment.

In sum, seven models were developed to describe expressed contractors' satisfaction levels based on client performance. Several performance (i.e. client and project) attributes and satisfaction (i.e. assessor and company assessor) attributes were found to influence levels of 
satisfaction. The predictive performance of the models was then tested against independent data that had not been used in the development of the models. The results suggested that the models were valid and robust (refer to Appendix C). Therefore, the models could be used to predict contractor satisfaction levels arising from client performance for the betterment of client performance and successful project implementation. This would help to promote the development of harmonious working relationships within the construction PC.

\section{IMPLICATIONS AND POTENTIAL PRACTICAL APPLICATIONS OF THE}

\section{MODELS}

The models identified the key determinants of contractor satisfaction levels arising as a consequence of client performance. Although some determinants are somewhat beyond the control of participants (e.g. type of projects) and may be due to for example subjectivity, some are within the control of participants. These determinants will enhance satisfaction levels if they are effectively addressed, particularly in the early stages of project development. Participants (i.e. clients and contractors) should focus on these determinants in order to enhance satisfaction levels and ultimately achieve better participant and project performance. The following paragraphs describe the implications of the research findings for the construction project coalition.

\section{Implications for the project coalition}

At the commencement of a construction project, the client appoints a project manager to act as their representative responsible for project execution and a contact point for the service providers to the client organisation. Given this crucial role, this representative should be carefully selected. Capable representatives greatly influence other client performance attributes and hence enhance the performance of the client. For example, capable 
representatives should be appropriately qualified, have a good track record in project management, be able to eliminate, minimise or resolve disputes on site, and ultimately reduce the propensity for litigation. A capable representative should also be able to facilitate effective communication allowing information to be made available and decisions to be reached as early as possible. Here, clients need to delegate proper levels of authority to their representatives. To achieve these, the client's representative should demonstrate sufficient technical skills to be able to broadly understand the scope, complexity and technology involved, as well as sufficient people-management skills to foster a client focus in the production of the project (Walker, 1994; 1995; 1998). Specifically, client’s representatives should be able to retain high levels of confidence from their construction and design teams. The client's representative should:

- be sophisticated in terms of knowing what is involved with the project, its scope and complexity, and are able to offer and accept advice about both the design and construction;

- have good communication skills;

- have good team-building and interpersonal skills; and

- clearly communicate the priorities of the client's objectives (Walker, 1998).

With these skills, the client's representative should also be able to initiate the support and proactiveness of all participants. This, therefore, will improve client performance which in turn will enable the other participants to perform better.

Prior to commencement of construction work on site, it is preferable for the design to be as complete as possible as this shares a positive relationship with contractor satisfaction levels. Once the project commences, attempts should be made to keep the project to budget. This requires a concerted approach from all participants involved which will be underpinned by 
the use of some kind of relationship-based procurement route, such as partnering and strategic alliances. Good and open communication, and collaboration between participants should be maintained throughout the course of the project. This in turn will result in the maintenance of team trust and cohesiveness.

A degree of subjectivity was indicated in the performance assessment on behalf of contractors. While subjectivity is difficult to change since it concerns an individuals' perception, this may be changed in the long term if, for example, clients and their representatives are willing to be involved in the construction process and attempt to improve their performance for the betterment of project performance.

\section{Potential practical applications of the models}

The models could be used to predict satisfaction levels by contractors and clients (as an assessor and a performer) at the earliest possible stage in the project life cycle. While, as an assessor, contractors could predict their satisfaction levels based on the performance of their clients, as a performer, clients could predict the satisfaction levels of the contractors based on their own performance. While predicting contractor satisfaction levels by clients may be somewhat 'alien' for some, the argument delivered here is that mutual performance assessment, a willingness to be criticised constructively and cooperation among participants including clients, are essential for enhancing project performance and satisfaction levels.

The models are best utilised in the earlier stages of the project (e.g. initial project meetings) when corrective actions suggested by the models are more likely to influence final project outcomes. Predicted satisfaction levels would be determined through simple mathematical calculations considered suitably practical and easy to adopt by practitioners. The intention is 
to develop similar models for the other participants of the construction PC so that benefits of this process could be maximized, where each participant is able to achieve their maximum potential performance. The models would be specifically beneficial for partnering or strategic alliances because they would stimulate communication and cooperation among participants involved. Additionally, it is important that regular meetings be held, perhaps once a month (once a week at site level) or more frequent, particularly to address performance issues. Here, feedback on performance should be deemed as constructive. For example, the client

performance criteria compiled in this research (refer to Appendix A) may be useful in providing an indication of the clients' strengths and weaknesses. That is, to identify problems before they develop into conflicts. The 'assessment' requires a team effort including all coalition participants to pursue continuous improvement and satisfactory performance. Hence, the 'assessment' should be a mutual process in a real sense, supporting the development of long-term relationships and high satisfaction levels.

\section{REFERENCES}

Baker, B.N, Murphy, D.C. and Fisher, D. (1988) Factors affecting project success. In Project Management Handbook, $2^{\text {nd }}$ edition, Cleland, D.I. and King, W.R. (eds.). Van Nostrand Reinhold, New York.

Berry, W.D. and Feldman, S. (1993) Multiple regression in practice. In Regression analysis, Lewis-Beck, M.S. (ed.), International handbooks of quantitative applications in the social sciences, Sage Publications, Ltd., London.

Bohrnstedt, G.W. (1970) Reliability and validity assessment in attitude measurement. In Attitude measurement, Summers, G.F. (ed.), Rand McNally \& Company, Chicago, 8099. 
Bryman, A. and Cramer, D. (1999) Quantitative data analysis with SPSS Release 8 for Windows: A guide for social scientists. Routledge, London.

Carmines, E.G. and Zeller, R.A. (1979) Reliability and validity assessment. Quantitative applications in the social sciences series No. 17, Sage Publications, Ltd., London.

Cattell, R.B. (1978) The scientific use of factor analysis in behavioral and life sciences. Plenum Press, New York.

CIOB (1998/1999) Directory and handbook 1998/1999. Chartered Building Company Scheme. CIOB publications, Ascot.

Dun and Bradstreet (1998) Key British enterprises. Dun and Bradstreet, London.

Dunteman, G.H. (1994) Principal components analysis. In Factor analysis and related techniques, Lewis-Beck, M.S. (ed.), International handbooks of quantitative applications in the social sciences, Sage Publications, Ltd., London.

Edwards, D.J. (1999) A methodology for predicting the total average hourly maintenance cost of tracked hydraulic excavators operating in the UK opencast mining industry. Unpublished Ph.D. thesis, University of Wolverhampton.

Edwards, D.J. and Holt, G.D. (2000) Estivate: A model for calculating excavator productivity and output costs. Engineering, Construction and Architectural Management, 7(1), 5262.

Egan, J. (1998) Rethinking construction. The report of the Construction Task Force on the scope for improving quality and efficiency in UK construction. Department of the Environment, Transport and the Regions, London.

Fisher, R.A. and Yates, F. (1938) Statistical tables for biological, agricultural and medical research, $6^{\text {th }}$ ed. Longman, London.

Higgin, G. and Jessop, N. (1965) Communications in the building industry: the report of a pilot study. Tavistock Publications Limited, London. 
Holt, G.D. (1995). A methodology for predicting the performance of construction contractors. Unpublished Ph.D. thesis, University of Wolverhampton.

Johnson, M.D. and Fornell, C. (1991) A framework for comparing customer satisfaction across individual and product categories. Journal of Economic Psychology, 12, 267286.

Kim, J.O. and Mueller, C.W. (1978) Factor analysis: Statistical methods and practical issues. Quantitative applications in the social sciences series No. 14, Sage Publications, Ltd., London.

Kleinbaum, D.G. and Kupper, L.L. (1978) Applied regression analysis and other multivariable methods. Duxbury Press, North Scituate, Massachusetts.

Kompass (1999-2000) Register of British industry and commerce. Kompass Publisher Ltd.

Kvanli, A.H., Guynes, C.S. and Pavur, R.J. (1996) Introduction to Business Statistics: A Computer Integrated Approach, $4^{\text {th }}$ ed. West Publishing Company, St. Paul / Minneapolis.

Lewis-Beck, M.S. (1993) Applied regression: An introduction. In Regression analysis, Lewis-Beck, M.S. (ed.), International handbooks of quantitative applications in the social sciences, Sage Publications, Ltd., London.

Litwin, M.S. (1995) How to measure survey reliability and validity. Sage Publications, Ltd., Thousand Oaks, California.

Liu, A.M.M. \& Walker, A. (1998) Evaluation of project outcomes. Construction Management and Economics, 16, 209-219.

Mohsini, R.A. (1989) Performance and building: problems of evaluation. Journal of Performance of Constructed Facilities, 3(4), 235-242.

Norusis, M.J. (1994) SPSS Professional Statistics 6.1. SPSS Inc., Chicago. 
Norusis, M.J. (1995) SPSS 6.1: Guide to data analysis. Prentice Hall, Englewood Cliffs, New Jersey.

Nunnally, J.C. (1978) Psychometric theory, $2^{\text {nd }}$ ed. The McGraw-Hill Companies, Inc., New York.

Oliver, R.L. (1997) Satisfaction: a behavioral perspective on the consumer. The McGrawHill Companies, Inc., New York.

Sargent, D. (2000) A presentation in workshop entitled 'Do your customers get satisfaction?' held at the Engineering Employers' Federation, Broadway House, London SW1 on 5 April 2000. In Workshop report, Construction Productivity Network, CIRIA.

Smith, A. and Wilkins, B. (1996) Team relationships and related critical factors in the successful procurement of health care facilities. Journal of Construction Procurement, 2(1), 30-40.

Smith, P.C., Kendall, L.M. and Hulin, C.L. (1969) The measurement of satisfaction in work and retirement: a strategy for the study of attitudes. Rand McNally \& Company, California.

Swan, J.E. and Combs, L.J. (1976) Product performance and consumer satisfaction: A new concept. Journal of Marketing, 40, 25-33.

Torbica, Z.M. (1997) Total quality management and customer satisfaction in home building. Unpublished Ph.D. dissertation, University of Florida.

Walker, D.H.T. (1994) Procurement systems and construction time performance, in Proceedings of CIB W92 Symposium, East meets West, Rowlinson, S. (ed), CIB Publication no: 175, Hong Kong University, Hong Kong, pp. 343-351.

Walker, D.H.T. (1995) The influence of client and project team relationships upon construction time performance. Journal of Construction Procurement, 1(1), 4-20. 
Walker, D.H.T. (1998) The contribution of the client representative to the creation and maintenance of good project inter-team relationships. Engineering, Construction and Architectural Management, 5(1), 51-57. 


\section{APPENDIX A: PRINCIPAL COMPONENT ANALYSIS (PCA) OF CLIENT PERFORMANCE CRITERIA}

With regard to the measurement of an abstract concept (such as satisfaction), Nunnally (1978) described how combined scores were more valid and reliable than individual scores alone. However, the combination of criteria should be based on a methodology that is sound (i.e. based on statistical analysis) and be both logical and interpretable.

In order to achieve this, the principal component analysis (PCA) technique was applied to the performance criteria of 55 responses (i.e. case projects). The main purpose was to determine the number of common components (i.e. satisfaction dimensions) that would satisfactorily produce the correlations among the observed variables (Kim and Mueller, 1978). The number of components was determined based on the criteria that the eigen value for each component should be greater than 1 , and the examination of the scree plot of components' eigen values. To achieve the simplest possible component structure in order to obtain more interpretable components, promax oblique rotation with the power (Kappa) valued at 4 was utilised. Oblique rotation (instead of orthogonal rotation) was utilised since it allows the presence of correlations between components / dimensions. In fact, this assumption concurs with the real life situation since one aspect of performance should be, to some extent, related to other aspects (Cattell, 1978; Bryman and Cramer, 1999 p.279). Furthermore, Norusis (1994) claimed that oblique rotations have often been found to yield substantively meaningful components since it is likely that influences in nature are correlated.

The component structure matrix (as shown in Table A1, column 3-7) was examined to identify the performance criteria for each component / dimension. Each dimension consists of several performance criteria, which have highest loading on that dimension. Performance 
criteria that had their second highest loading within 0.10 of their highest ones were not used to define any dimension (i.e. deleted) (Torbica, 1997). This is because these criteria do not uniquely contribute to any dimension.

Performance criteria under each dimension were then averaged to obtain the satisfaction measure (i.e. component score). From the original 33 performance criteria, 22 were allocated to a particular component. Criteria coded M3, M4, S1, S2, S3, S4, A5, A6, A7, A8 were included in satisfaction measure-1 (satis1) representing 'support provided to contractors'. Satis2 consisted of A1, A2, A3, A11 indicating 'clients' attitude'. Satis3 covered U4, U5, U6, M1 representing 'clients' understanding of their own needs'. Criteria coded U1, U2, U3 were included in satis4 indicating the 'quality of clients' brief'. Criteria coded F1, F2 representing 'financial aspects of performance' were covered in satis5. The component score serves as an index of attitude towards a particular dimension of concept under investigation (Torbica, 1997). In this case, unweighted performance criteria were used in preference to weighted ones (Torbica, ibid.). Nunnally (1978) claimed that weighted performance criteria are often unstable and seldom make an important difference. It is said that seeking differential weights is almost never worth the trouble (Nunnally, ibid.).

\section{APPENDIX B: MULTIPLE REGRESSION (MR) TECHNIQUE}

As the purpose of the analysis was to develop models to predict levels of satisfaction (i.e. a matter of degree, not an all or none property / satisfied or dissatisfied), the multiple regression (MR) technique was chosen as the modelling tool. Moreover, preliminary data examination showed a degree of linear relationship between dependent and independent variables. This indicates that MR is an ideal methodology for data of this nature (Lewis-Beck, 1993). The model takes a general form in the following (Lewis-Beck, ibid.): 


$$
Y=a_{0}+b_{1} X_{1}+b_{2} X_{2}+b_{3} X_{3}+\ldots . .+b_{n} X_{n}+e
$$

where $Y$ is dependent variable (i.e. satisfaction measure), $a_{0}$ is a constant indicating intersect with Y axis, $b_{n}$ are partial regression coefficients, $X_{n}$ are independent variables, and $e$ is the error term.

The stepwise method for inclusion / exclusion of independent variables was utilised. This is the most commonly used method for model building (Norusis, 1995). F-statistics with probability of $5 \%$ and $10 \%$ were employed for entry and removal criteria. Although popular, the stepwise procedure has been claimed to be controversial because it includes independent variables based on statistical criteria and not theoretical ones (Bryman and Cramer, 1999). This means independent variables showing highest correlation with satisfaction measures will be included, adversely, independent variables which are less correlated will be excluded from the model. This does not mean that these variables are not important, they just explain the same thing and are superfluous from an analytical (not theoretical) point of view (Kleinbaum and Kupper, 1978; Kzranowski, 1988 cited in Edwards, 1999). The models were investigated for possible violation of the regression assumptions, i.e. normal distribution of residual, equality of variance, and linearity. The results confirmed that the required assumptions for MR had been met.

\section{APPENDIX C: MODEL VALIDATION}

The predictive performance of the models was assessed by examining the residual (i.e. the difference between the actual and the models' predicted satisfaction measures). These were measured using two prediction performance measures, i.e. mean absolute deviation (MAD) and mean absolute percentage error (MAPE) (Kvanli et al., 1996). Mean absolute deviation (MAD) can be calculated using the following formula: 
$\mathrm{MAD}=\frac{\sum_{i=1}^{n} \mathrm{AD}_{i}}{n}$

and

$\mathrm{AD}_{i}=\left|x_{i}-p_{i}\right|$

where $\mathrm{AD}_{i}$ is the absolute deviation of satisfaction measure for case project $i, x_{i}$ is the actual value of satisfaction measure for case project $i, p_{i}$ is the predicted value of satisfaction measure for case project $i$, and $n$ is the number of case projects (respondents). Mean absolute percentage error (MAPE) can be calculated using this formula:

$\mathrm{MAPE}=\frac{\sum_{i=1}^{n} \mathrm{APE}_{i}}{n}$

and

$\mathrm{APE}_{i}=\left|\frac{x_{i}-p_{i}}{x_{i}}\right| \times 100 \%$

where $\mathrm{APE}_{i}$ is the absolute percentage error of case project $i$. These formulas conclude that a model yields predicted values with an average deviation of \pm MAD, which is MAPE \% from actual values. MAPE can also be used for model comparison (Kvanli et al., 1996). For data of this nature, MAD of 1.5 to 2.0 and MAPE of 30 to 35\% are still considered acceptable. MAD of less than 1 and MAPE of less than 20\% indicate good predictive performance. 
The performance of the models were also tested using chi-square $\left(\chi^{2}\right)$ analysis and Pearson's correlation coefficient (Edwards, 1999). The null hypothesis $\left(H_{0}\right)$ for $\chi^{2}$ test is that there is no significant difference between the actual and predicted values of satisfaction. A two-tailed test was used because the hypothesis aims to determine whether there is a difference at all and not simply an improvement (as with a one-tailed test) (Edwards and Holt, 2000). This implies that the model has consistent predictive performance at the $5 \%$ level of significance (Edwards and Holt, ibid.). The $H_{0}$ for Pearson's correlation test is that there is no correlation between predicted and actual satisfaction measures. Here, a one-tailed test was used. This was to confirm that the satisfaction measures can be predicted with a significant level of accuracy, using the given independent variables in a multiple regression model (Edwards and Holt, ibid.).

The models were validated using a hold-back samples of 17 questionnaires (i.e. case projects) that had not been used to develop the model. The results as presented in Table C1 confirmed the robustness of the models in predicting contractor satisfaction levels. 
Table 2 Multiple regression models of contractor satisfaction based on client performance

Satisfaction models

Support provided to contractors $=1.291+0.578$ (capability of the client's representative)

-1.481 (overbudget cost)

+0.163 (distance of the project from the client's home office)

+0.01577 (percentage of design completed before commencement of work on site)

Clients' attitude $=5.256+0.526$ (capability of the client's representative)

-2.021 (overbudget cost) -1.138 (industrial building project)

Clients' understanding of their own needs $=4.293+0.579$ (capability of the client's representative)

-0.298 (perception that clients always change their mind)

-1.185 (industrial client)

Quality of clients' brief $=3.359+0.711$ (client's past performance and project management experience)

-0.213 (perception that clients always want to minimise cost without considering quality)

Financial aspects of performance $=0.719+0.906$ (client's financial soundness and reputation)

Average satisfaction $=0.224+0.459$ (capability of the client's representative)

+0.379 (client's financial soundness and reputation)

+0.0001045 (contractor size measured in terms of number of employees)

+0.110 (client's communication channel)

Overall satisfaction $=3.653+0.717$ (capability of the client's representative)

-1.745 (overbudget cost)

-0.328 (perception that clients always change their mind)

+0.223 (perception that clients do not know what they want)

Note: $\mathrm{R}^{2}$ (i.e. coefficient of determination) indicates proportion of variance explained by significant independent variables 


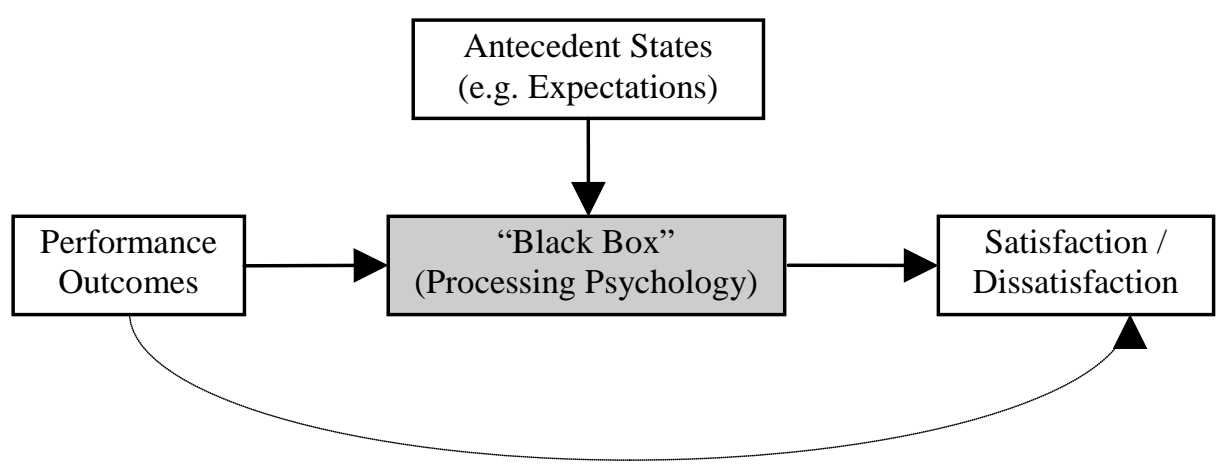

Figure 1 A mediated performance model of satisfaction (after Oliver, 1997)

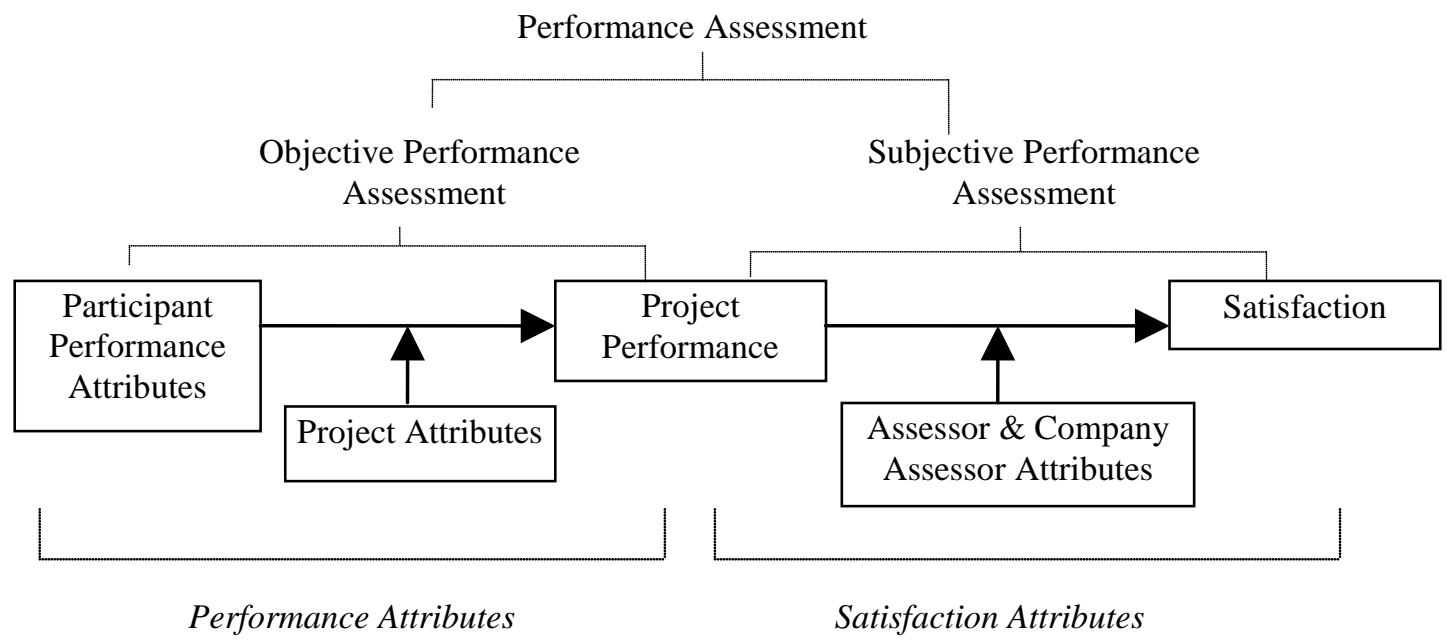

Figure 2 Conceptual research model 


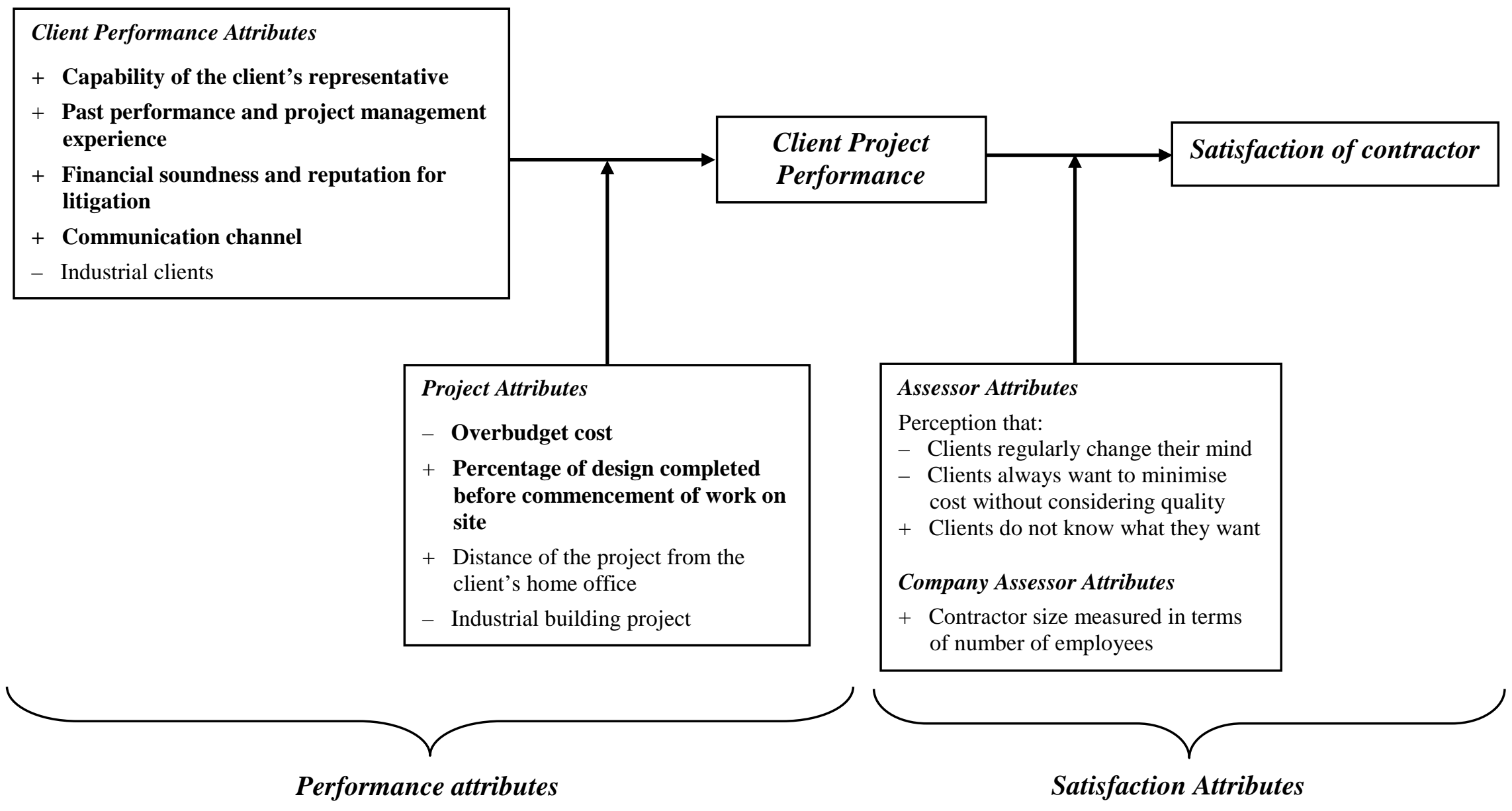

Figure 3 Summary of contractor satisfaction models based on client performance 